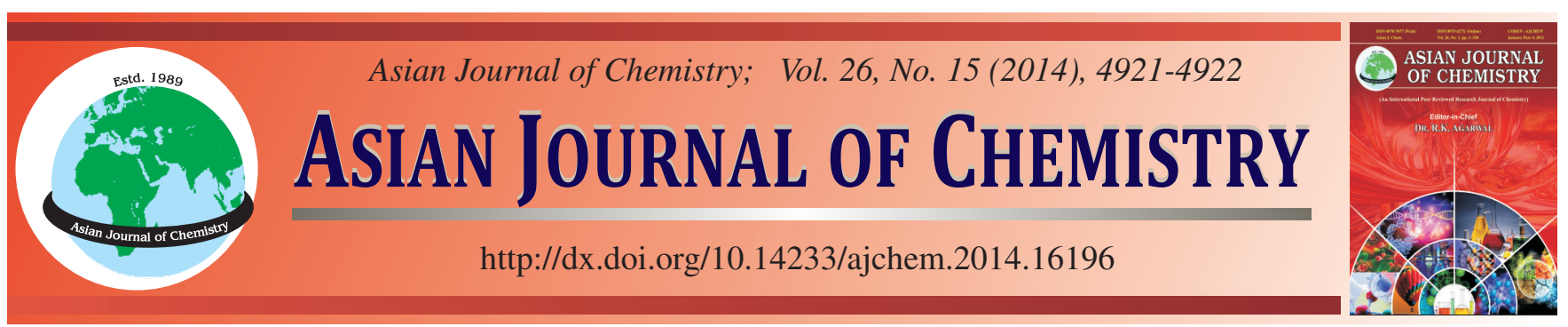

NOTE

\title{
Solidified Floating Organic Drop Microextraction for Determination of Trace Amounts of Copper in Water Samples by Flame Atomic Absorption Spectrometry
}

\author{
Qi Feng Liu, Yan Li Dong, Jing Jun MA* and Jing Ci Li ${ }^{*}$
}

Hebei Key Laboratory of Bioinorganic Chemistry, College of Sciences, Agricultural University of Hebei, Baoding, P.R. China

*Corresponding authors: Fax: +86 312 7528292; Tel: +86 312 7528291; E-mail: mjjwjpmartin@ sina.com

Received: 16 August 2013;

Accepted: 18 December 2013;

Published online: 16 July 2014;

AJC-15601

A simple and efficient microextraction method for extraction and determination of trace amounts of copper in different water samples has been developed using solidified floating organic drop microextraction combined with flame atomic absorption spectrometry. 1-Dodecanol and $\mathrm{NaDDTC} \cdot 3 \mathrm{H}_{2} \mathrm{O}$ were used as extracting solvent and chelating agent, respectively. Under the optimized experimental conditions, a good relative standard deviation of $3.62 \%$ at $500 \mu \mathrm{g} \mathrm{L}^{-1}$ and a detection limit of $0.3270 \mu \mathrm{g} \mathrm{L}^{-1}$ were obtained. The procedure was applied to different water samples and its accuracy was assessed through the analysis of certified reference water and recovery experiments.

Keywords: Solidified floating organic drop microextraction, Flame atomic absorption spectrometry, Preconcentration, Copper.

Copper is a widespread anthropogenic pollutant of the environment. Determination of copper is a current problem. The removal of copper from aqueous media such as effluents is of great interest for environmental and human health purposes ${ }^{1,2}$. Recently, much interest and effort have been devoted to studies on copper determination in water and biological matrices, to provide good tools for environmental and toxicological monitoring. However, the level of copper in surface water and groundwater is too low to easily determine accurately. To solve this problem, a separation/preconcentration step prior to analysis is required. Not long ago, a new liquid-liquid microextraction method, solidified floating organic drop microextraction (SFODME) was proposed for extraction and determination of organic analytes $^{3-5}$. It has the advantages of simplicity, low cost, minimum organic solvent consumption and high enrichment factor. We extend its application to inorganic analysis ${ }^{6,7}$.

In this work, a study of the SFODME for preconcentration of copper in water samples after the formation of a complex with $\mathrm{NaDDTC} \cdot 3 \mathrm{H}_{2} \mathrm{O}$ and its determination by FAAS.

A Hitachi Z-5000 Atomic Absorption Spectrometer (Japan) equipped with Zeeman background correction was used in the experiment. A Model LD5-2A centrifuge (Beijing, P.R. China) was used to accelerate the phase separation. A $59 \mathrm{kHz}$, $200 \mathrm{~W}$ ultrasonic bath with temperature control (Shanghai, P.R. China) was used to assist the emulsification process of the micro-extraction technique. All chemicals were high-purity grade reagents and at least of analytical reagent grade.
In a $10 \mathrm{~mL}$ test tube with a conical bottom, $5.0 \mathrm{~mL}$ of 500 $\mu \mathrm{g} \mathrm{L}^{-1} \mathrm{Cu}^{2+}$ solution or water samples, $1.0 \mathrm{~mL}$ of phosphate buffer and $2.0 \mathrm{~mL}$ of DDTC solution were mixed. The solution was sonicated for $15 \mathrm{~min}$ at $59 \mathrm{kHz}$. In this step, $\mathrm{Cu}$ ions react with DDTC. Then $60 \mu \mathrm{L}$ of 1-dodecanol was added using a $100 \mu \mathrm{L}$ syringe. The conical tube was transferred into the ultrasonic bath again to ensure complete extraction. The mixture was then centrifuged for $2 \mathrm{~min}$ at $2000 \mathrm{rpm}$. After this process fine droplets of 1-dodecanol coalesced and the organic solvent collected at the surface of sample solution. The conical test tube was transferred into an ice bath and the organic solvent was solidified after $5 \mathrm{~min}$. The solidified solvent was then transferred into another conical vial where it melted immediately. After this process, the extract was diluted to $500 \mu \mathrm{L}$ with ethanol and manually injected into the flame atomic absorption spectrometer.

In the selection of an appropriate extraction solvent, 1-bromohexadecane (m.p. $<15^{\circ} \mathrm{C}$ ), hexadecane (m.p. 17$19{ }^{\circ} \mathrm{C}$ ) and 1-dodecanol (m.p. $23-25^{\circ} \mathrm{C}$ ) were investigated. In the present study, 1-dodecanol was selected as extracting solvent because it gives better extraction efficiency than the other solvents. To evaluate the effect of the extraction solvent volume, different volumes of 1-dodecanol in the range of 20$120 \mu \mathrm{L}$ were used in the preconcentration procedure. The analytical response increased slowly as the solvent volume increased in the range of $20-60 \mu \mathrm{L}$, then it was nearly constant as the solvent volume increased from 60 to $120 \mu \mathrm{L}$. In order to 
decrease the pollution to the environment and ensure complete extraction, $60 \mu \mathrm{L}$ was selected as the most suitable volume of extraction solvent.

The $\mathrm{pH}$ of the sample solution is one of the important factors affecting the formation of a metal complex and its extraction. Fig. 1 displays the effect of $\mathrm{pH}$ on the $\mathrm{Cu}$ signal intensity. In the $\mathrm{pH}$ range of 6-9, the signal intensity of $\mathrm{Cu}$ was nearly constant. Therefore, a $\mathrm{pH}$ of 6 was selected for subsequent work. Under the optimum $\mathrm{pH}$, the effect of the volume of chelating agent DDTC on the analytical signal was studied. The maximum absorbance was obtained with $2 \mathrm{~mL}$ of the ligand which is the optimum amount of DDTC.

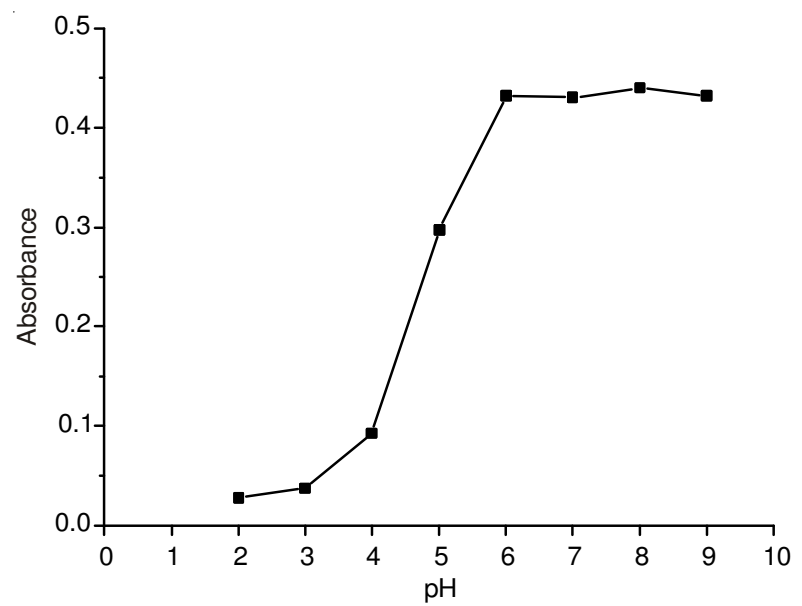

Fig.1. Effect of $\mathrm{pH}$ on extraction of copper by the SFODME method. Extraction conditions: water sample volume, $5.0 \mathrm{~mL}$; amount of copper, $2.5 \mu \mathrm{g}$

The effect of extraction time on extraction efficiency was examined in the range of 5-30 min with a constant ultrasonic frequency. The FAAS signals of copper were increased by increasing the extraction time up to $15 \mathrm{~min}$. After $15 \mathrm{~min}$, the extraction efficiency remained nearly constant. Thus, $15 \mathrm{~min}$ was selected as the extraction time. To determine the influence of the extraction temperature, the process was studied by varying the temperature between $25^{\circ} \mathrm{C}$ and $55^{\circ} \mathrm{C}$; the results revealed that the maximum absorbance was obtained at $45^{\circ} \mathrm{C}$. Higher or lower temperature will lead to the reduction of the analytical signal. Hence, $45{ }^{\circ} \mathrm{C}$ is recommended for further studies.

As other condition was optimized, it was very crucial to pay more attention to the coexisting ions because they may influence the enrichment in most cases. Herein, an investigation was performed for this purpose. The experiment result 1000-, 1000-, 50-, 50-, 10-, 20-, 20-, 10- and 1000-folde (molar ratio of ions/Cu) of $\mathrm{Na}^{+}, \mathrm{K}^{+}, \mathrm{Mg}^{2+}, \mathrm{Ca}^{2+}, \mathrm{Pb}^{2+}, \mathrm{Cd}^{2+}, \mathrm{Ni}^{2+}, \mathrm{Co}^{2+}$ and $\mathrm{CH}_{3} \mathrm{COO}-\left(\mathrm{C}_{2} \mathrm{O}_{4}{ }^{2-}, \mathrm{NO}_{3}{ }^{-}, \mathrm{Cl}^{-}, \mathrm{I}^{-}\right)$had no impact on the extraction of $\mathrm{Cu}$ with a concentration of $7.87 \times 10^{-6} \mathrm{~mol} \mathrm{~L}^{-1}$. For studying the influence of ionic strength, we investigated $\mathrm{NaCl}$ concentrations in the range of $0-5 \%(\mathrm{w} / \mathrm{v})$ while other experimental conditions were kept constant. Increasing the $\mathrm{NaCl}$ concentration had no significant effect on extraction efficiency. Therefore, all the extraction experiments were carried out without adding salt.

Related parameters such as detection limit, precision, linear range and preconcentration factor are important to a new developed method. Therefore, they were investigated to validate the applicability of the proposed method. Under the optimal conditions, it was found that the calibration equation, an excellent linear range, detection limit, precision and preconcentration factor were $\mathrm{A}=1.58 \times 10^{-3} \mathrm{C}+0.0397,20.0-800.0$ $\mu \mathrm{g} \mathrm{L}{ }^{-1}(\mathrm{R}=0.9989), 0.3270 \mu \mathrm{g} \mathrm{L}^{-1}, 3.62 \%(\mathrm{n}=6)$ and 86 , respectively.

In order to test the reliability of this methodology, it was applied to the determination of copper in several water samples such tap, sea, river and waste water samples which were collected in PTFE containers from Hebei province and filtered using a $0.45 \mu \mathrm{m}$ pore size membrane filter to remove suspended particulate matter and stored in a refrigerator in the dark. The results are given in Table-1. The recoveries of different concentrations of copper added to water samples were in the range 96.2-103.7\%. The results show that the proposed method is suitable for the determination of copper in such water samples.

\begin{tabular}{cccc}
\multicolumn{4}{c}{ TABLE-1 } \\
\multirow{2}{*}{$\begin{array}{c}\text { DETERMINATION OF CU IN REAL SAMPLES (RESULTS } \\
\text { OF RECOVERIES OF SPIKED SAMPLES) }\end{array}$} \\
\cline { 2 - 3 } Sample $=3)$ \\
\cline { 2 - 3 } & \multicolumn{2}{c}{ Copper amount $\left(\mu \mathrm{g} \mathrm{L}^{-1}\right)$} & \multirow{2}{*}{ Recovery $(\%)$} \\
\cline { 2 - 3 } Tap water & 0.0 & $2.89 \pm 0.20$ & - \\
& 5.0 & $7.70 \pm 0.36$ & 96.2 \\
Sea water & 0.0 & $8.61 \pm 0.28$ & - \\
& 10.0 & $18.98 \pm 0.35$ & 103.7 \\
River water & 0.0 & $7.25 \pm 0.26$ & - \\
& 10.0 & $17.06 \pm 0.33$ & 98.1 \\
Waste water & 0.0 & $15.70 \pm 0.23$ & - \\
& 10.0 & $25.82 \pm 0.25$ & 101.2 \\
\hline
\end{tabular}

From the experiment result, it can be concluded that SFODME is an efficient method for determination of copper. Minimum use of toxic organic solvent, simplicity, low cost, rejection of matrix constituents, enhancement of sensitivity and rapid analysis time are the major advantages of the use of SFODME. The proposed method can be applied to determination of trace quantities using various ligands and assessment of the multi-element enrichment capability of the method for trace determination in various water samples and other environmental samples.

\section{ACKNOWLEDGEMENTS}

This project was sponsored by the Development Foundation of the Department of Education of Hebei Province (No. zh2011128) and the Research Development Foundation of the Agricultural University of Hebei (No. LG201305).

\section{REFERENCES}

1. J.L. Manzoori and A. Bavili-Tabrizi, Microchem. J., 72, 1 (2002).

2. V.A. Lemos, J.S. Santos and P.X. Baliza, J. Braz. Chem. Soc., 17, 30 (2006).

3. M.R. Khalili Zanjani, Y. Yamini, S. Shariati and J.Å. Jönsson, Anal. Chim. Acta, 585, 286 (2007).

4. H. Farahani, Y. Yamini, S. Shariati, M.R. Khalili-Zanjani and S. MansourBaghahi, Anal. Chim. Acta, 626, 166 (2008).

5. H.R. Sobhi, Y. Yamini, A. Esrafili and R.H.H.B. Abadi, J. Chromatogr. A, 1196-1197, 28 (2008).

6. S. Dadfarnia, A.M. Salmanzadeh and A.M.H. Shabani, Anal. Chim. Acta, 623, 163 (2008).

7. S. Dadfarnia, A.M. Haji Shabani and E. Kamranzadeh, Talanta, 79, 1061 (2009). 